\title{
Development of Simulation for Predicting Maintenance Costs for Educational Facilities
}

\author{
Jong-Hwa Park and Jong-Young Youn and Donghoon Lee* \\ Department of Architectural engineering Hanbat National University Daejeon 34158 Republic of Korea. \\ *Corresponding author. Tel.: +82-010-2663-9331; Email address:donghoon@ hanbat.ac.kr
}

Article History: Received:11 november 2020; Accepted: 27 December 2020; Published online: 5 April 2021

\begin{abstract}
In Korea, educational facilities are managed after issues are detected. Furthermore, due to imprecisely estimated maintenance costs, there are problems in managing educational facilities such as excessive budgets, etc. it is impossible to accurately estimate costs for various cases such as repairs and damages. Thus, the overall maintenance costs were analyzed based on probability of cases that may occur. This study proposes a system that predicts maintenance subjects and maintenance costs using probability values and that predicts the total maintenance cost through simulations. This study used simulations to accurately predict maintenance costs in various unexpected situations. The study was carried out by classifying into three categories according to each feature. The features were described according to the type of each item and simulation of the categorized items were produced separately to calculate the expected price. In the case of 'annual fixed expenses', the total of the maintenance cost tended to increase with a secondary curve where the slope gradually grows with time. In the case of 'irregular expenses due to repairs/changes caused by minor failures', maintenance cost had a certain cycle according to a failure rate according to the life of each item and an inflation rate of $1.9 \%$ was applied to show a tendency for occurrence to grow. In the case of 'Replacement/repair costs according to the scheduled period for the entire educational facility', the simulation results showed that each item had a constant cycle depending on the replacement period and that facility maintenance costs did occur. This study presumed data for simulations, but did not verify it. By supplementing such limitations, it will be possible to produce a reliable simulation model. The expected effect of reducing budget waste by predicting the exact cost of educational facilities through simulation.
\end{abstract}

Keywords: Educational facilities, Maintenance cost, Cost prediction, Simulation production, Failure rate.

\section{Introduction}

Facility management can extend the life of facilities and ensure safety for users, and when facilities are not managed, it can save on costs for resolving issues. However, facility management in Korea is currently performed only after problems with facilities are discovered[1]. Numerous studies have been conducted to make improvements to this, but the problem is yet to be solved[2]. In the past, the sole purpose of educational facilities was to satisfy the demand of students. But now, it is being constructed to organically respond to the ever-quickly changing education system and the number of higher education institutes is growing by the year. Under such circumstances, the need to maintain the facilities of higher educational institutes in order to provide safer and more effective education has been rising, and more effective facility maintenance and management than previous is now needed.

Therefore, this study identified the current situation in which educational facility maintenance costs were inaccurately predicted, thus resulting in excessive budget allocation. As a new facility management plan for this, this study aims at presenting a simulation and developing a simulation model to manage educational facilities. The scope of educational facilities subject to this study was limited to educational facilities including elementary, middle and high schools, as well as undergraduate and postgraduate schools in Korea.

This study was carried out with the following method. First, studies were made on the contents related to facility management. Afterwards, a theoretical study was made on the simulation to apply the simulation in this study. Next, after defining the scope, purpose and variables of the simulation for applying it, facility management data of educational facilities were collected, and the simulation was produced. Lastly, after producing the simulation, actual data was applied to activate the simulation, and it was reviewed to check for problems within the produced simulation.

\section{Theoretical Study}

\subsection{Facility Maintenance}

Article 2 of the 'Special Act on the Safety Control and Maintenance of Facilities' defines 'facilities' as 'any structure built through construction works and facilities incidental to such structure, which is classified into a Class-I and Class-II facility establishment referred to in Subparagraphs 2 and 3'[2].In the same law, it defines 'maintenance' as 'preserving the functions of a completed facility and routinely inspecting and maintaining to enhance the convenience and safety of facility users, and other activities necessary for improving, repairing and reinforcing the facility, as required over time to restore damaged areas to the original state'[2].

Facilities in Korea have vulnerabilities compared to advanced countries due to common practices of cutting construction costs and construction periods after the 1970s. But follow-up management of facilities were not

*Corresponding author: Donghoon Lee

Department of Architectural engineering Hanbat National University Daejeon 34158 Republic of Korea.

Email address:donghoon@hanbat.ac.kr 
conducted appropriately. Amidst such circumstances, large construction accidents occurred one after the other such as the Independence Hall fire in 1986, and the collapse of Paldang Bridge in 1991, Changseon Bridge and Shinhaengju Bridge in 1992, and Cheongju Uam Plaza Apartment in 1993. Despite ongoing faulty construction and incidents, the need for maintenance relied solely at the discretion of the managers. In result, Seongsu Bridge collapsed in 1994 and after this incident, awareness on the importance of safety and maintenance for facilities grew. Accordingly, the government enacted the 'Special Act on the Safety Control and Maintenance of Facilities' to systemize safety and maintenance of facilities, while placing duties and responsibilities for maintenance to facility managers and also fostered competent expert institutes to carry this our professionally.

\subsection{State of Educational Facility Maintenance}

The mode of Korean educational facilities have been changing ceaselessly from the past to this day. Accordingly, studies on maintaining educational facilities have been ongoing, but still, improvements were not made in many areas[4]. [Table 1] explains the contents on facility status, legal systems, business changes, and maintenance before and after 2000, and it describes the features by era regarding personnel, business and entity for maintenance.

Table1 School Facility Maintenance Trends Before and After 2000[2]

\begin{tabular}{|c|c|c|c|}
\hline \multicolumn{2}{|c|}{ Division } & Before 2000 & After 2000 \\
\hline \multicolumn{2}{|c|}{ Facility status } & - simplification & - Complexity \\
\hline \multicolumn{2}{|c|}{ legal systems } & $\begin{array}{l}\text { - local finance law } \\
\text { - Elementary and Secondary } \\
\text { Education Law }\end{array}$ & $\begin{array}{l}\text { - Special Act on Safety Management of } \\
\text { Facilities } \\
\text { - Private investment law for infrastructure } \\
\text { facilities }\end{array}$ \\
\hline \multicolumn{2}{|c|}{ Business changes } & - Financial business & $\begin{array}{l}\text { - Private consignment management } \\
\text { business } \\
\text { - BTL business }\end{array}$ \\
\hline \multirow{3}{*}{ Maintenance } & Personnel & $\begin{array}{l}\text { - Main duties of facility } \\
\text { managers }\end{array}$ & $\begin{array}{l}\text { - Decrease in skilled work, Increase in } \\
\text { female civil servants, Increase in civilians }\end{array}$ \\
\hline & Business & $\begin{array}{ll}\text { - School centered } \\
\text { maintenance }\end{array}$ & - Private Trust, Conduct BTL \\
\hline & Entity & $\begin{array}{l}\text { - Office of education, } \\
\text { Supervise School }\end{array}$ & - Office of education, School, Private \\
\hline
\end{tabular}

Educational facility management entities are divided into three groups such as the local Office of Education, school and private companies, and due to the lack of communication among the parties, there are impediments to smooth progress of work. Therefore, there are limitations in providing high quality education to students who are the users of educational facilities.

There is also the problem that there is still no law that was enacted regarding educational facility management in Korea. Due to its nature, educational facilities are subject to different management compared to general apartment housing and other public facilities, and the annual maintenance cost calculation method should also be conducted differently from that of apartments and public facilities. But because there is no law established on managing educational facilities in Korea, it follows the 'Enforcement Decree of the Housing Act'. It is thus judged that laws on educational facilities in Korea should be enacted promptly

\subsection{Related Research Trends}

Studies on facility maintenance have been ongoing since 2007. Past studies analyzed in this study were mainly on research for educational facility maintenance work process improvement plans, calculation of e ducational facility maintenance expenses, and research on periodical calculation for maintenance per item. The table that summarizes these studies are as shown in [Table 2].

Table2 Previous Studies on Educational Facility Maintenance

\begin{tabular}{c|l|c|c}
\hline No. & \multicolumn{1}{|c|}{ Title } & Author & y \\
\hline 1 & $\begin{array}{l}\text { A Study on the Maintenance System Improvement for Public Educational } \\
\text { Buildings[1]. }\end{array}$ & $\begin{array}{c}\text { Kim, Tae- } \\
\text { Whi }\end{array}$ & 2007 \\
\hline
\end{tabular}




\begin{tabular}{|c|c|c|c|}
\hline 2 & $\begin{array}{l}\text { A Case Study on the Improvement Plan for Cost Prediction of Educational BTL } \\
\text { Project based on Running Cost Analysis[2] }\end{array}$ & $\begin{array}{l}\text { Park, Moon- } \\
\text { Sun }\end{array}$ & 2007 \\
\hline 3 & $\begin{array}{l}\text { A Study on the Estimating method for Annual Maintenance Costs of Educational } \\
\text { Facilities[3] }\end{array}$ & Son, Jae-Ho & 2012 \\
\hline 4 & $\begin{array}{l}\text { Looking for ways to improve quality of school facility maintenance and } \\
\text { management:Focused on School Facilities in Ulsan Metropolitan Office of } \\
\text { Education[4] }\end{array}$ & $\begin{array}{l}\text { Park, Sang- } \\
\text { Mo }\end{array}$ & 2017 \\
\hline 5 & A Study on School Facility Maintenance Improvement Plan[5] & $\begin{array}{l}\text { Lee, Mi- } \\
\text { Sun, }\end{array}$ & 2010 \\
\hline 6 & A Study on Effective Counterplan of School Building Maintenance[6] & $\begin{array}{l}\text { Park, Sung- } \\
\text { Choon }\end{array}$ & 2007 \\
\hline 7 & $\begin{array}{l}\text { A basic study on cost prediction model based on repair and replacement causes by } \\
\text { using probabilistic forecasting concept[7] }\end{array}$ & $\begin{array}{l}\text { Yu, Yeong- } \\
\text { Jin }\end{array}$ & 2017 \\
\hline 8 & $\begin{array}{l}\text { Analysis of Maintenance costs through the Maintenance Cycle and Maintenance } \\
\text { Cost Ratio for Educational Building[8] }\end{array}$ & $\begin{array}{l}\text { Song, } \\
\text { Chang- } \\
\text { Young }\end{array}$ & 2013 \\
\hline 9 & Maintenance Case and Cost Analysis for University Facilities[9] & $\begin{array}{c}\text { Shin, } \\
\text { Myeong-Ha }\end{array}$ & 2016 \\
\hline
\end{tabular}

Song, Chang-young (2013) conducted a study with the goal of analyzing maintenance costs by finding the appropriate repair period and repair costs for educational facilities that are pursued in BTL (Build Tran sfer Lease) order methods. Park, Sang-mo (2017) drew up issues with schools through surveys on school f acility management. A study on optimization of system operation through the combination of preceding ca ses to achieve the goal of the organization was carried out and a systematic linking management system o f school facility administrators and the Office of Education was provided.

$\mathrm{Yu}$, Yeong-Jin (2017) conducted basic research for the development of the cost prediction simulation $\mathrm{m}$ odel according to the cause for repair or replacement of those subject to facility maintenance through prob ability estimation. He performed studies for computing maintenance costs using Monte Carlo Simulation. T he repair costs of educational facilities were estimated using (Equation 1) for simulation modeling.

$$
R=F \times S
$$

$\mathrm{Yu}$, Yeong-Jin (2017) conducted basic research for the development of the cost prediction simulation $\mathrm{m}$ odel according to the cause for repair or replacement of those subject to facility maintenance through prob ability estimation. He performed studies for computing maintenance costs using Monte Carlo Simulation. T he repair costs of educational facilities were estimated using (Equation 1) for simulation modeling.

$$
\rho(\chi)=\frac{1}{\sqrt{2} \pi} e^{-\frac{z^{2}}{2}}
$$

By continuing research in the future based on these research results, it is expected that it will contribute $g$ reatly in developing a cost prediction model according to the cause of repair and replacement.

\section{School Facility Maintenance Items}

\subsection{School Facility Maintenance Items Categories}

Upon analyzing past studies, maintenance costs were estimated using the total maintenance cost in the past, but it was a maintenance cost estimation method that did not consider the characteristics per item. There were only a few studies that estimated maintenance costs by dividing into each item and they are maintenance cost estimation methods that excluded unexpected situations. Therefore, it is necessary to have a maintenance cost calculation plan that can respond to all situations. A simulation was developed in this study as a method for computing maintenance costs. For this, the types of each item were selected through literary studies in this study and expenditure costs were classified as shown in [Table 3] to analyze predicted costs. Accordingly, this study has the following distinctions to make improvements to past studies.

Table3 Maintenance Cost Classifications[2]

1. Fixed Expenses 
Water, electricity, facility management costs, building cleaning costs, outsourcing management costs for communication equipment, rental and management costs for drinking water purifiers, expense costs, landscaping management costs, chemical and electrical equipment (telephone, intercom, TV, broadcasting) Cost, computer communication network, unmanned security facility), cleaning supplies purchase cost

\section{Irregular Expenses due to Minor Failures}

Elevator failure repair costs, heat pump air conditioner failure repair costs, broadcasting facility failure repair costs, boiler failure repair costs, computer and beam projector and other mechanical equipment repair costs, partial paint repainting costs, doorway repair costs Expenses, sidewalk block replacement costs, urinal urinal repair costs, replacement costs due to damage to windows and insect screens, replacement costs due to falling wall tiles, replacement costs due to floor tile damage, ceiling tex replacement costs due to water leaks, etc.

\section{Expenses due to Regular Replacements}

Air conditioner heat pump replacement cost, whole floor tile replacement cost, paint repainting cost for entire building, structural reinforcement, parking lot repair cost, playground lawn replacement cost, LED light replacement cost, stairway repair replacement cost, School building cost

\subsection{Fixed Expenses}

First, fixed expenses will be similar to previous expenses unless there are large variables every year. Items falling under this are the most basic costs for operating facilities such as electricity fees, water fees, etc. and inflation, which has an effect, is almost the same. A variable that may occur at a rare probability is a situation in which the costs for each item rises or drops at an independent rate without following the inflation rate. [Figure 1] is a graph on the maintenance costs spent at a constant rate.

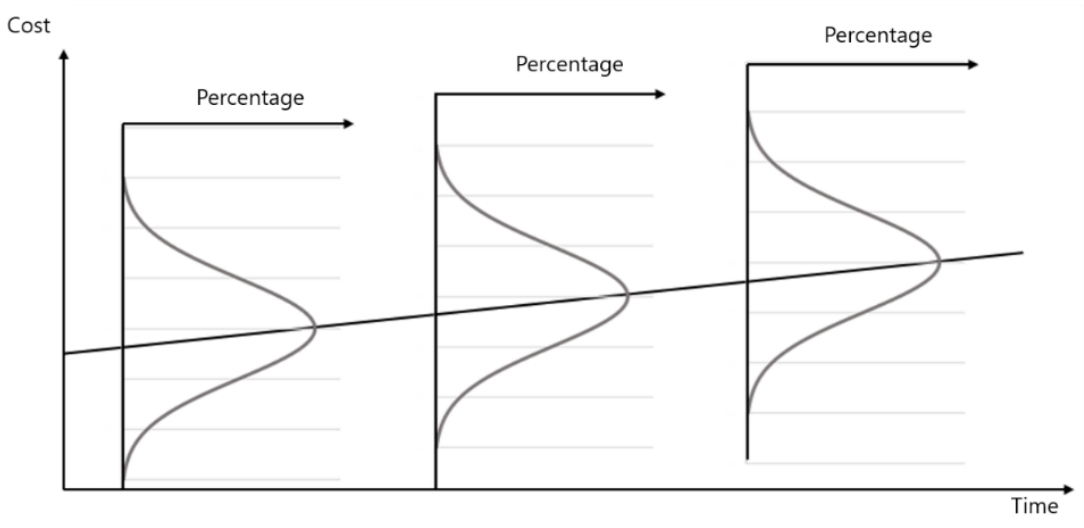

Figure 1 Cost Graph of Items with Fixed Annual Expenditure

Costs spent by these items show a fixed rising line in the graph due to inflation rates. At this time, no other variables except inflation are presumed and as each cost is not a precisely determined value, but a predicted value, it is assumed that it follows a statistically standard normal distribution.

\subsection{Irregular Expenses due to Minor Failures}

Secondly, there are costs for repairs resulting from minor failures or damages in items such as air conditioners, doors, windows, etc. of educational facilities. In this case, the rate of failures and damages are not constant, and therefore, the costs are not constant either, but the failure frequency trends can be predicted. This study used the following failure rate function to predict the failure frequency of these items.

$$
\lambda(t)=\frac{\mathfrak{f}(t)}{\mathcal{R}(t)}=\frac{\lambda e^{-\lambda t}}{e^{-\lambda t}}=\lambda=\frac{1}{M T B F}=\frac{1}{\theta}
$$


The In (Equation 3), $\lambda$ is defined as the mean failure rate1/MTBF. MTBF Is the abbreviation of Mean Time Between Failure and in this study, it means the time between failure and failure, or in other words, the life of the part, and $\theta$ is defined as mean life.

When expressing failure rate for a single item using a failure graph, it can be expressed as shown in [Figure 2]. According to the failure rate function, tendency lines of failure rates for a single item increase from the normal zone to the complete failure zone, and complete failure occurs when failure rate reaches 1 , which is when the part must be repaired or replaced. At this time, the value of the failure rate is more statistic than definitive. Hence, it has statistical values that follow the probability distribution in which each value is very low during the initial period after completing construction of the facility, and as time passes, the probability for failure rises.

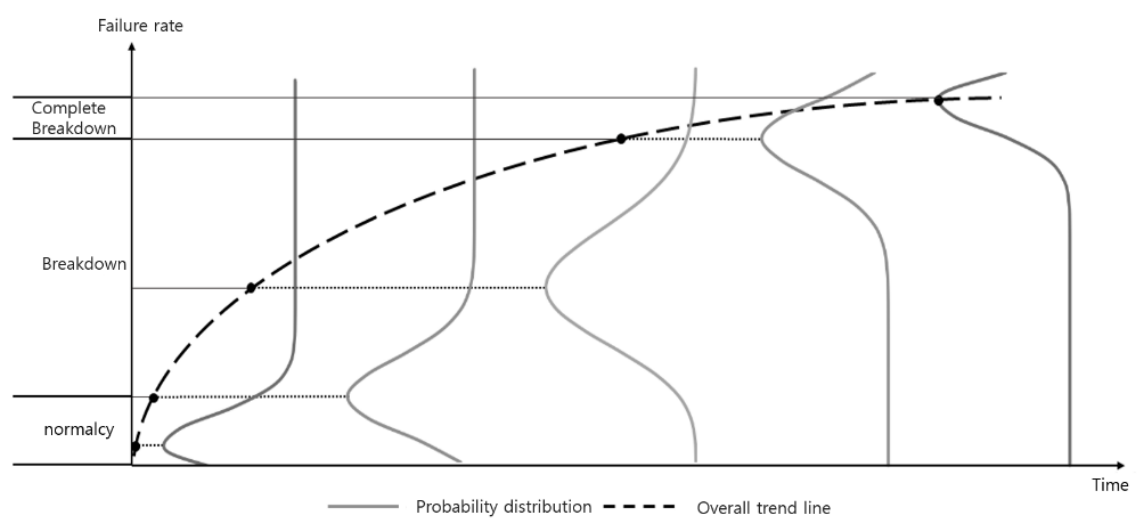

Figure 8 Meaning of 'A' and 'B' Areas

\subsection{Expenses due to Regular Replacements}

In the case of educational facilities, the entire educational facility is replaced or repaired due to the two reasons below. The first is because of the high failure rate of the item subject to maintenance. The administrator must repair or replace various parts that make up educational facilities such as equipment, doors, windows, etc. depending on the level of failure or damage. But when problems occur for an entire educational facility with the passage of time, it must be replaced, repaired or modified in its entirety.

In this case, the probability for replacement of each item increases with time. Afterwards, the entire facility must be replaced or repaired at some unknown point in time. Afterwards the entire replacement or repair probability of each item returns to the initial value and then the failure probability increases gradually with the same form as previous.

The second case is when replacing the corresponding item according to the repair/replacement cycle of each facility. In this case, maintenance is performed according to the replacement and repair cycle suggested by the government or the relevant company regardless of damages or failure of the corresponding item. Also, in this case, it has a definitive value rather than a probability value according to the replacement cycle of each item. In other words, 'do or do not perform overall replacement and repairs'. This occurs in one of the two cases.

\section{Simulation Production}

\subsection{Fixed Expenses}

First is the production of a simulation for costs spent at a fixed rate annually. Costs to be placed in the simulation were set for one year and the past costs per item were presumed, and the simulation for entering inflation was produced as shown in [Figure 3]. Also, in the case of annual basic management funds deduced through this study, an inflation rate of $1.9 \%$ was applied compared to the same month of the previous year as of October 2018. The produced simulation treats inflation rate and basic management costs as input and the annual basic management cost through the simulation as output. 

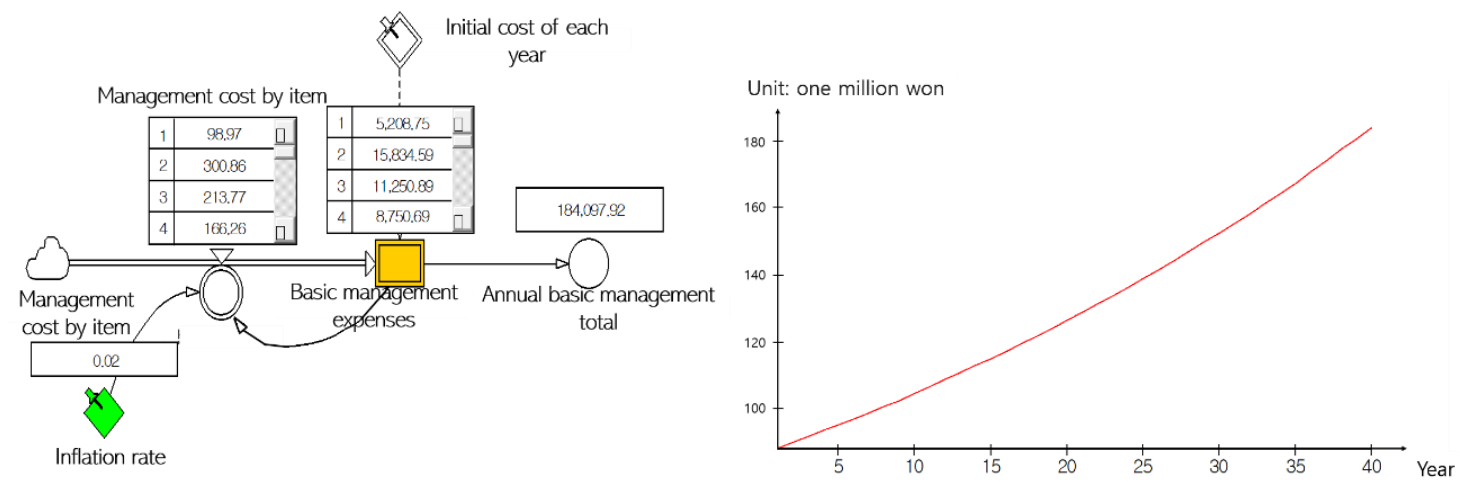

Figure 3 Basic Management Cost Simulation Applying Inflation Rates and Cost Prediction Graph

The sum of the predicted costs of the following items can be expressed as a graph as shown in [Figure 3]. The sum of the basic management costs is $0 \mathrm{KRW}$ at the time of completing the construction and it gradually increases as time passes. This is also interpreted to be the result of being influenced by inflation and when setting the inflation rate higher, it is expected that the graph will show a steeper increase. Meanwhile, if the inflation rate is set lower, the slope of the graph is expected to be softer. In [Figure 3], if the inflation rate is set higher, the increase in the graph is also expected to have a more rapid incline.
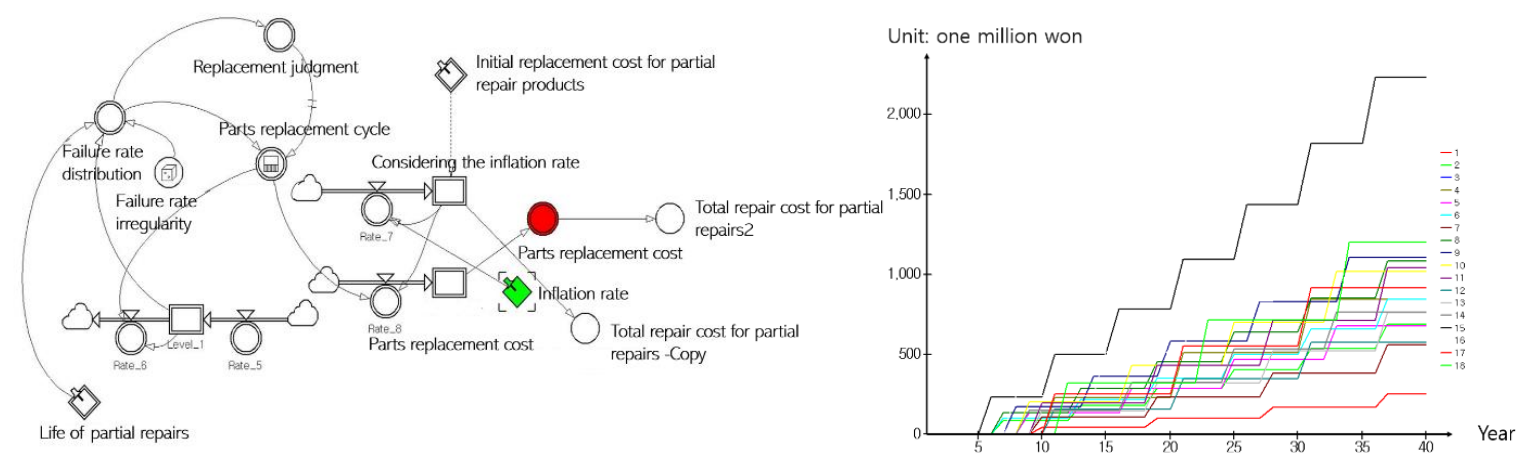

Figure 4 Partial Repair Item Cost Prediction Simulation Model and Predicted Maintenance Cost Graph

But there is the problem that failure rate functions do not consider unexpected situations. Therefore, it is necessary to respond to be able to respond to all situations. According to the failure rate function, when computing maintenance cost for all educational facilities, facilities and mechanical equipment installed at the same time incur failure regularly in the same period. But as the probability that failure will occur according to the failure rate function in reality is very low, there are cases where situations other than failure rate functions occur. Next, we need plans to compute maintenance costs. The number of failures cannot be identified perfectly, but it is possible to predict the number of failures that occur in the following period according to trends.

Based on such results, simulations were produced for 'irregular expenses due to minor failures'. But due to lack of real data, issues with applying failure functions, difficulties in limiting various variables, and other areas that need supplementation through follow-up research, there are limitations in the simulation. Based on the results of this study, by continuously carrying out studies on the production of simulations to predict 'irregular expenses due to minor failures', it is judged that it will contribute to more accurate computation of maintenance costs.

\subsection{Expenses due to Regular Replacements}

Lastly, a simulation model was produced when having to make repairs or replacements to the entire educational facility. Repairs and replacements for the entire education facility are carried out in two different cases. The first is when replacing the entirety due to failure rates of each item. When it is judged that the entire item must be repaired or replaced at the discretion of the educational facility administrator, there are many cases in which it is replaced regardless of the life of the item.

The second case is when replacing according to the replacement cycle of the corresponding item. In the case of Korea, the durable years are explicated by law for various items such as facility type, materials, parts, etc. There are cases in which repairs and replacements are carried out according to the durable years of each item. 
Therefore, simulation models are produced for each of the two situations in this study. The simulation model is produced by focusing on the first case and using the second case in a secondary role. In other words, the simulation model was produced to perform repairs and replacements according to a certain replacement period even if a random item does not have failures even after a certain period of time passes,

Simulation was produced for the first case. For this, the simulation model considering the status change according to failure rate per item was produced as shown in [Figure 5]. At this time, the status of the regular replacement part uses regular replacement parts as input to find the output.

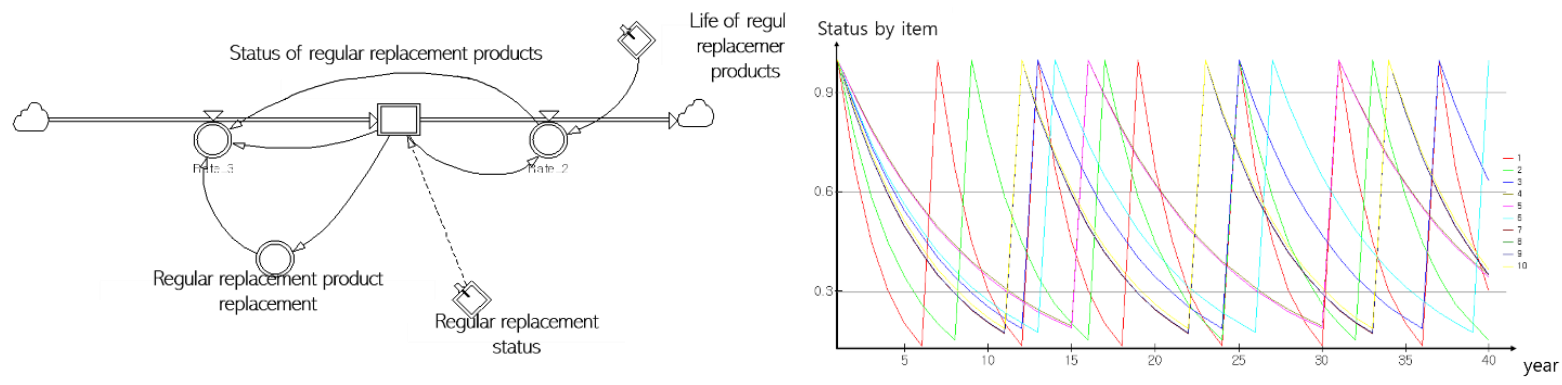

Figure 5 Results on Simulation Model and Status Change Considering State of Each Item according to Failure Rate

When looking at the simulation results of [Figure 5] in a graph, the state of each item is close to complete when it is near 1 and incomplete when near 0. Like the failure rate, it is evident that the state of each item returns to the original state according to the specified period through repairs and replacements whenever failures occur like the failure rate. When presuming that replacement is made when status value is 0 , replacement costs do not occur until the status value of each item becomes 0 , and only when the status value becomes 0 , it was found that replacement costs occurred.

Next, a simulation model was produced to predict maintenance costs per item in reality, and the simulation model is as shown in [Figure 6]. This is a simulation model produced to predict actual costs by adding simulations considering the replacement period per item for the simulation in [Figure 5]. The simulation model in [Figure 6] uses the life of each item as input to compute the status value according to time of each item. Afterwards, the replacement period and replacement cost of each item were used as input and would replace the said item when it becomes the replacement period before the status value of each item becomes 0 .

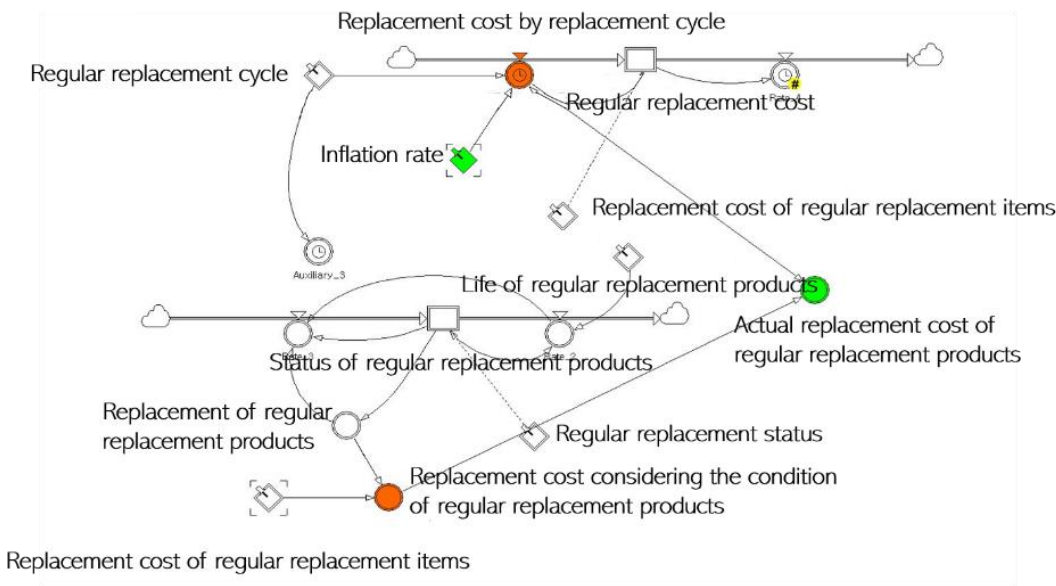

Figure 6 Expected Cost Simulation according to Replacement Period of Regular Replacement Parts

When expressing the actual replacement costs through the simulation model, it is as shown in [Figure 6]. Because the status and replacement period of each item is considered, it was found that the period was more irregular. It was also found that the predicted value gradually increases as time passes by applying the inflation rate, and it was found that the actual replacement period of items with short life can become even shorter 


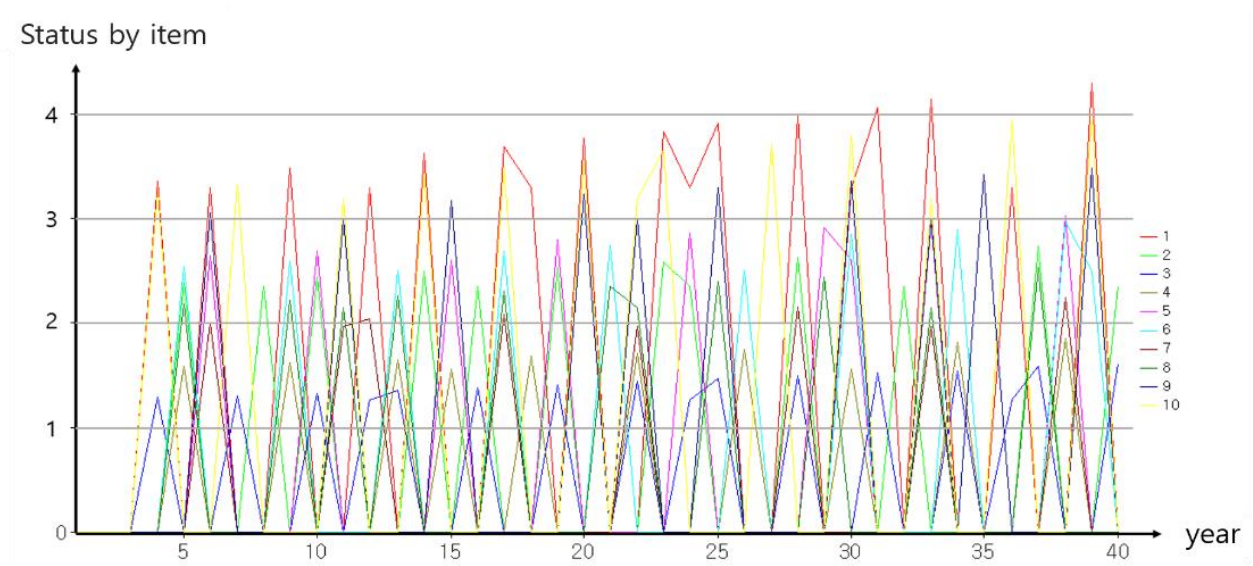

Figure 7 Actual Replacement Costs of Regular Replacement Items

This study categorized three maintenance items to accurately predict maintenance costs of educational facilities and used a tool called simulations. Through this, simulation models that can respond to various situations were produced, and it is thus expected to be able to predict highly reliable maintenance costs. But due to the lack of real data, it has the limitation that it was not possible to verify the simulation int his study, and it also has areas for improvement in that virtual data was used for producing the simulation. It is anticipated that it will be possible to produce a more reliable simulation model through follow-up research that supplements the above limitations.

\section{Conclusions}

This study was on computing facility maintenance costs by focusing on problems such as the state in which facility management is being conducted only after finding irregularities with facilities, the facility maintenance method that is not up to speed with the changes in school classrooms, excessive budget allocation for maintenance costs that are not accurately predicted, etc. This study used a simulation to predict maintenance costs more accurately in various unexpected situations, and referred to past studies to select the corresponding items. The study was carried out by classifying the selected items into three categories according to each feature in order to predict maintenance costs more accurately.

This study classified items subject to educational facility maintenance cost for simulation production.

1) Annual fixed expenses

2) Irregular expenses due to repairs/changes caused by minor failures

3) Replacement/repair costs according to the scheduled period for the entire educational facility

Afterwards, the features were described according to the type of each item and simulation of the categorized items were produced separately to calculate the expected price. It is expected that this study will make it possible to predict educational facility maintenance costs more accurately, and moreover, it will help with allocating budgets appropriately for each educational facility. But this study also includes a number of matters that require supplementation such as applying a specified inflation rate, not applying maintenance costs per item with precise numbers, and lack of data investigation for replacement periods for each item. If these are supplemented to continue the study, it is judged that it will be possible to calculate educational facility maintenance costs even more precisely. It is judged that this will help reduce wasted budgets excessively allocated to predict facility maintenance cost predictions that have thus far been inaccurate.

\section{Acknowledgements}

- This work is supported by the Korea Agency for Infrastructure Technology Advancement(KAIA) grant funded by the Ministry of Land, Infrastructure and Transport (Grant 20CTAP-C151959-02).

- This work was supported by the National Research Foundation of Korea(NRF) grant funded by the Korea government(MSIT)(2017R1C1B5076057).

not be long. Your article should be reviewed by all co-writers before submission.

\section{References}

1. Kim TH, Eom GC. A Study on the Maintenance System Improvement for Public Educational Buildings. Korea Institute of Ecological Architecture and Environment. 2007;7(3):81-8. Available from: 
http://www.ndsl.kr/ndsl/commons/util/ndslOriginalView.do?cn=JAKO200730360545537\&dbt=JAKO\&ko $\mathrm{i}=$ KISTI1.1003\%2FJNL.JAKO200730360545537.

2. Park MS, Song CY, Kim YS. A Case Study on the Improvement Plan for Cost Prediction of Educational BTL Project based on Running Cost Analysis. Korea Institute of Construction Engineering and Management. 2007;8(6):139-49. Available from: http://www.ndsl.kr/ndsl/commons/util/ndslOriginalView.do?cn=JAKO200709905857039\&dbt=JAKO\&ko $\mathrm{i}=\mathrm{KISTI} 1.1003 \%$ 2FJNL.JAKO200709905857039.

3. Son JH, Lee SH. A Study on the Estimating method for Annual Maintenance Costs of Educational Facilities. Korean Institute of Educational Facilities. 2012;19(5):21-8. Available from: http://www.ndsl.kr/ndsl/commons/util/ndslOriginalView.do?cn=JAKO201230554941461\&dbt=JAKO\&ko $\mathrm{i}=$ KISTI1.1003\%2FJNL.JAKO201230554941461.

4. Park SM. Looking for ways to improve quality of school facility maintenance and management [master's thesis]. Cheongju: Korea National University of Education; 2017 Feb. Korean. Available from: http://www.riss.kr/search/detail/DetailView.do?p_mat_type=be54d9b8bc7cdb09\&control_no=169498607e 0cd31fffe0bdc3ef48d419\&outLink=N.

5. Lee MS. A Study on School Facility Maintenance Improvement Plan [master's thesis]. Gyeongsan: Yeungnam University; 2010 Feb. Korean. Available from: http://www.riss.kr/search/detail/DetailView.do?p_mat_type=be54d9b8bc7cdb09\&control_no=b089427120 5f862bffe0bdc3ef48d419\&outLink=N.

6. Park SC. A Study on Effective Counterplan of School Building Maintenance [master's thesis]. Gwangju: Chonnam National University; 2007 Aug. Korean. Available from: http://www.riss.kr/search/detail/DetailView.do?p_mat_type=be54d9b8bc7cdb09\&control_no=2bfeb29539 2e7555ffe0bdc3ef48d419\&outLink=N.

7. Yu YJ, Son KY, Kim TH, Kim JM. A basic study on cost prediction model based on repair and replacement causes by using probabilistic forecasting concept. Spring Annual Conference of Architectural Institute of Korea. $2017 \quad ; 37(1): 887-90 \quad 61 . \quad$ Available from: http://www.dbpia.co.kr/journal/articleDetail?nodeId=NODE07178706.

8. Song CY. Analysis of Maintenance costs through the Maintenance Cycle and Maintenance Cost Ratio for Educational Building. The Regional Association of Architectural Institute of Korea. 2013 Jun;15(3):15361. Available from: https://www.earticle.net/Article/A200167.

9. Shin MH, Lee CS. Maintenance Case and Analysis for University Facilities. Korean Institute of Educational Facilities. 2016;23(6):27-34. DOI: https://doi.org/10.7859/kief.2016.23.6.027

10. Seok HS, Cho CY, Kim JO, Son JH. A Study on Deduction of Reasonable Inspection Time in Educational Facilities Based on Regression Analysis. Korean Institute of Educational Facilities. 2007;14(4):34-42. Available from: http://www.dbpia.co.kr/journal/articleDetail?nodeId=NODE07051413. 